\title{
Diabetes mellitus adversely affects mortality and recurrence after valve surgery for infective endocarditis
}

\author{
Daisuke Yoshioka, MD, , ${ }^{\text {,b }}$ Koichi Toda, MD, ${ }^{\mathrm{a}}$ Jun-ya Yokoyama, MD, ${ }^{\mathrm{a}}$ Ryohei Matsuura, MD, ${ }^{\mathrm{a}}$ \\ Shigeru Miyagawa, MD, ${ }^{\mathrm{a}}$ Satoshi Kainuma, MD, ${ }^{\mathrm{a}}$ Taichi Sakaguchi, MD, ${ }^{\mathrm{c}}$ Masayuki Sakaki, MD, \\ Hiroyuki Nishi, MD, ${ }^{\mathrm{e}}$ Yukitoshi Shirakawa, MD, ${ }^{\mathrm{f}}$ Keiji Iwata, MD ${ }^{\mathrm{g}}$ Hitoshi Suhara, MD, ${ }^{\mathrm{h}}$ \\ Ryoto Sakaniwa, MPH, ${ }^{\mathrm{i}}$ Hirotsugu Fukuda, MD, ${ }^{\mathrm{j}}$ Osaka Cardiovascular Research Group study group, and \\ Yoshiki Sawa, MD
}

\section{ABSTRACT}

Background: Although diabetes mellitus (DM) increases the incidence of infective endocarditis (IE), little is known about the outcome of valve surgery for active IE in patients with DM. We evaluated the clinical outcomes of valve surgery for IE in patients with DM.

Methods: Between 2009 and 2016, 470 patients underwent valve surgery for definitive left-sided active IE at 12 affiliated hospitals. We compared the preoperative variables and clinical outcomes between patients without $(\mathrm{n}=374)$ and with DM $(\mathrm{n}=96)$.

Results: Staphylococcus and chronic hemodialysis were more prevalent in patients with DM, and these patients had greater preoperative inflammation levels and worse renal function than patients without DM. In-hospital mortality was $8 \%$ in patients without DM and $13 \%$ in patients with $\mathrm{DM}(P=.187)$. The overall survival rate at 1 and 5 years was $87 \%$ and $81 \%$ in patients without DM and $72 \%$ and $59 \%$ in patients with $\mathrm{DM}(P<.001)$. The incidence of infection-related death was greater in patients with DM than in patients without DM $(P<.001$; hazard ratio 3.74 [1.78-7.71]). Freedom from the recurrence of endocarditis at 1 and 5 years postoperatively was $98 \%$ and $95 \%$ in patients without DM, and $89 \%$ and $78 \%$ in patients with DM $(P<.001)$, respectively. The Cox hazard analysis revealed that the presence of DM was the only independent risk for recurrence (hazard ratio 3.74 [1.45-9.54], $P=.007$ ).

Conclusions: The short- and mid-term outcome after valve surgery for active IE in patients with DM is worse because of the greater prevalence of infection-related death and IE recurrence. (J Thorac Cardiovasc Surg 2018;155:1021-9)

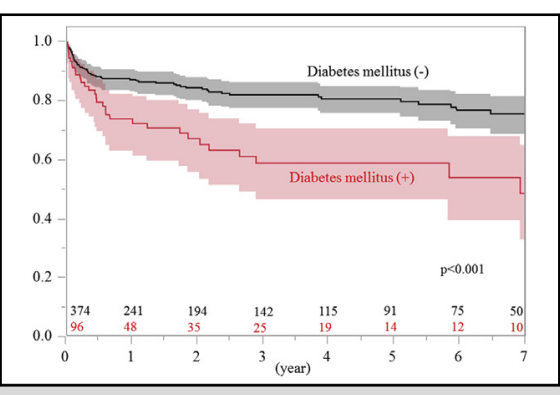

The Kaplan Meier analysis of the overall survival after valve surgery in patients with and without diabetes.

\section{Central Message}

The mid-term outcome after valve surgery for active endocarditis in patients with diabetes mellitus is worse because of the greater prevalence of infection-related death and endocarditis recurrence.

\section{Perspective}

Diabetes mellitus adversely affects infectionrelated death and endocarditis recurrence even after the successful discharge after valve surgery. The indication and timing of valve surgery in endocarditis should be evaluated in patients with diabetes. In addition, the prophylactic management about prevention of recurrence might be required in patients with endocarditis who have diabetes mellitus.

See Editorial Commentary page 1030.

\footnotetext{
From the ${ }^{\mathrm{a} D e p a r t m e n t ~ o f ~ C a r d i o v a s c u l a r ~ S u r g e r y, ~ O s a k a ~ U n i v e r s i t y ~ H o s p i t a l ; ~}{ }^{\mathrm{d}}$ Osaka National Hospital; ${ }^{e}$ Osaka Police Hospital; ${ }^{\mathrm{f}}$ Osaka Prefecture General Hospital; ${ }^{\mathrm{g}} \mathrm{JCHO}$ Osaka Hospital; and ${ }^{\mathrm{i}}$ Department of Public Health, Osaka University Graduate School of Medicine, Osaka; ${ }^{b}$ International University of Health and Welfare Mita Hospital, Tokyo; ${ }^{\mathrm{c}}$ Heart Center Sakakibara Hospital, Okayama; ${ }^{\mathrm{h}} \mathrm{Kinan}$ Hospital, Wakayama; ${ }^{\mathrm{j} D o k k y o}$ University Medical School Hospital, Tochigi, Japan.

Received for publication July 22, 2017; revisions received Aug 23, 2017; accepted for publication Sept 6, 2017; available ahead of print Oct 9, 2017.

Address for reprints: Daisuke Yoshioka, MD, Yamadaoka, 2-2, Suita-city, Osaka 565-0871, Japan (E-mail: yoshioka@surg1.med.osaka-u.ac.jp). $0022-5223 / \$ 36.00$

Copyright (c) 2017 by The American Association for Thoracic Surgery

https://doi.org/10.1016/j.jtcvs.2017.09.013
}

Despite the recent advances in the diagnosis and treatment of infective endocarditis (IE), it remains a disease with a high mortality rate. ${ }^{1}$ Several studies have evaluated the

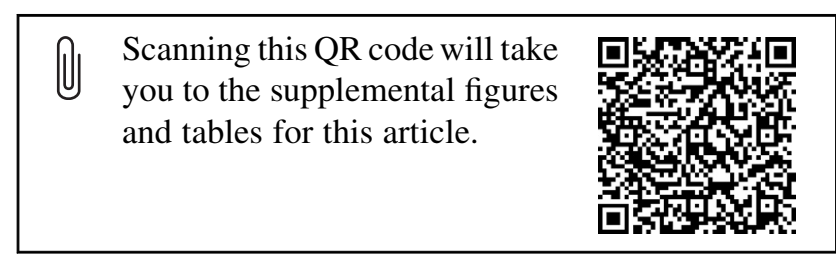




\section{Abbreviations and Acronyms \\ $\mathrm{CVA}=$ cerebrovascular accident \\ CVVHD $=$ continuous veno-venous hemodialysis \\ $\mathrm{DM}=$ diabetes mellitus \\ eGFR = estimated glomerular filtration rate \\ IE = infective endocarditis \\ $\mathrm{LV} \quad=$ left ventricular}

risk factors for mortality in patients with $\mathrm{IE}^{2,3}$ and found that surgical intervention reduced the rate of mortality. ${ }^{3-5}$

Meanwhile, it is well known that diabetes mellitus (DM) is associated with an increased risk of infections, ${ }^{6,7}$ and an epidemiologic study reported that DM increased the risk of IE. ${ }^{8}$ In addition, several previous studies have reported that $\mathrm{DM}$ is associated with an increased disease severity and in-hospital mortality rate in patients with IE. $^{4,9-12}$ However, approximately one half the patients in all these previous studies did not undergo surgical treatment. Moreover, mid-term to long-term clinical outcomes, particularly in patients with valve surgery, were not studied, and very little is known about the prognosis of patients with DM who are diagnosed with IE after valve surgery. Therefore, in the present study, we evaluated the clinical outcomes, including the short- and mid-term results, of surgical intervention for IE in patients with DM.

\section{METHODS \\ Study Design}

This retrospective, multicenter study was approved by the institutional review board of the Osaka University Hospital, and the use of the Osaka Cardiovascular Research Group database was approved by each affiliated hospital. Detailed records of patients who underwent valve surgery for active left-sided IE between 2009 and 2016 in 12 affiliated hospitals were obtained (Table E1). During this period, $470 \mathrm{pa}-$ tients underwent valve surgery for left-sided active IE. We compared the preoperative valuables and clinical results between patients with DM and patients without DM.

\section{Surgery and Postoperative Treatment for Active Endocarditis}

The indication and details of valve surgery were described previously. ${ }^{13}$ To summarize, as this was a retrospective multicenter study, the timing of valve surgery was decided by the attending surgeon at each hospital. The choice between valve repair or replacement and between mechanical valve or biological valve was at the discretion of the attending surgeon. Regarding the mitral valve endocarditis, mitral valve repair was attempted first if the infection and valve destruction were not extensive.

The postoperative antibiotics regimen was selected according to the guideline. ${ }^{14}$ Generally, intravenous antibiotics were administered for 4 weeks after the surgery, and the need for additional intravenous and/or oral antibiotic treatment was decided by each physician depending on the patient's condition.

\section{Definitions}

Left-sided active IE was defined as IE that involved the aortic valve or the mitral valve and required antibiotic therapy until the surgery. Patients with healed IE and IE that only involved right side valve were excluded from this study. The timing of IE diagnosis was defined as the day on which the presence of vegetation was first confirmed via transthoracic or transesophageal echocardiography. In patients without obvious vegetations, the timing of diagnosis was defined as the day on which they first met modified Duke criteria for definitive endocarditis. ${ }^{15}$ As for initial intention-to-treat plan, "medical treatment first" was defined as the initial treatment with antibiotics and medication for endocarditis without any decision of definitive timing and plan for valve surgery at the timing of endocarditis diagnosis, whereas "surgery first" was defined as the initial treatment with immediate planning for urgent or emergent surgery at the timing of endocarditis diagnosis.

In the present study, the presence of DM was defined as the chronic administration of oral medication for DM and/or subcutaneous insulin use, or preoperative glycated hemoglobin level greater than $6.5 \%$. Insulin use also was defined as requirement of chronic insulin use before the diagnosis of IE and/or since the discharge after valve surgery. Temporal intravenous and/or subcutaneous insulin infusion in the acute phase after surgery was not included into insulin use. Atrial fibrillation included both chronic and paroxysmal atrial fibrillation that was detected preoperatively. The presence of preoperative hemodialysis was defined as chronic hemodialysis for end-stage renal failure. Hypertension was defined as any preoperative episode of medical treatment for hypertension. The definition of other preoperative complications (eg, heart failure, stroke, and embolism), and postoperative complication (eg, neurologic deterioration and complete atrioventricular block) was described previously. ${ }^{13}$ Short- and mid-term mortality was defined as death for any reason. Cardiovascular-related death was defined as death due to a cardiovascular disease, which included stroke, heart failure, sudden death, prosthetic valve endocarditis, and acute myocardial infarction. Cerebrovascular accident (CVA)-related death was defined as any death due to a major stroke. Infection-related death was defined as death due to any infection (eg, recurrence of endocarditis, pneumonia). Endocarditis recurrence was defined as IE that required redo valve surgery for definitive prosthetic valve endocarditis or definitive endocarditis that met Duke criteria and required prolonged intravenous antibiotics therapy.

\section{Laboratory and Echocardiographic Values}

The causative organism was defined as an organism that was detected in a blood culture or a resected valve culture. If the definitive causative agents were not obtained from both blood cultures and resected valves, the causative organism was defined as unknown. Echocardiographic parameters were obtained at the time of diagnosis of IE. Vegetation size was determined based on the maximal length of the vegetation. Preoperative laboratory valuables were obtained from medical records at the time of endocarditis diagnosis and just before valve surgery. The laboratory valuables that were taken at the same day or at least 1 day before surgery was adopted for "laboratory data just before surgery." Several laboratory valuables (white blood cell counts and serum C-reactive protein, creatinine, and total bilirubin levels) also were collected postoperatively (at 1, 2, 4, and 8 weeks after the valve surgery). Estimated glomerular filtration rate (eGFR) was calculated with the following equation: eGFR $=186 \times$ (serum creatinine/ $88.4)^{-1.154} \times(\text { age in years })^{-0.203} \times 0.742$ (if female) .

\section{Data Collection}

Data collection of studied patients was mainly organized by 3 surgeons (Y.D., Y.J., and M.R.). Patient identification was performed with the Osaka Cardiovascular Research Group database, and details were collected by examining each hospital's medical records. The operative records of all patients also were reviewed, and the details of surgical procedures were collected. Follow-up investigations were performed with the information obtained from medical records or telephone contact by a physician in each hospital. In the present study, the median follow-up period was 2.2 (0.4-4.9) years. Follow-up was complete in $98 \%$ of cases as of December $31,2016$. 
TABLE 1. Baseline characteristics of the overall cohort

\begin{tabular}{|c|c|c|c|c|c|c|}
\hline & $\frac{\text { Diabetes mellitus (-) }}{\mathbf{n}=374}$ & $\frac{\text { Diabetes mellitus }(+)}{\mathbf{n}=96}$ & $P$ value & $\begin{array}{c}\text { Insulin (-) } \\
\mathbf{n}=\mathbf{5 6}\end{array}$ & $\begin{array}{c}\text { Insulin (+) } \\
\mathbf{n}=\mathbf{4 0}\end{array}$ & $P$ value \\
\hline \multicolumn{7}{|l|}{ Baseline characteristics } \\
\hline Age, y & $62(49-71)$ & $66(58-75)$ & $<.001$ & $66(63-75)$ & $63(56-74)$ & .106 \\
\hline Male, n (\%) & $241(64 \%)$ & $64(67 \%)$ & .720 & $42(75 \%)$ & $22(55 \%)$ & .050 \\
\hline Body surface area, $\mathrm{m}^{2}$ & $1.54 \pm 0.18$ & $1.60 \pm 0.21$ & .092 & $1.60 \pm 0.16$ & $1.60 \pm 0.24$ & .988 \\
\hline Body mass index, $\mathrm{kg} / \mathrm{m}^{2}$ & $20.7(18.4-22.8)$ & $22.3(19.9-26.6)$ & .006 & $21.7(20.1-24.4)$ & $23.0(19.7-28.5)$ & .382 \\
\hline \multicolumn{7}{|l|}{ Bacterial species } \\
\hline Positive blood culture, n (\%) & $280(75 \%)$ & $80(83 \%)$ & .104 & $47(84 \%)$ & $33(83 \%)$ & 1.000 \\
\hline Staphylococcus sp & $103(28 \%)$ & $37(39 \%)$ & .045 & $20(36 \%)$ & $17(43 \%)$ & .530 \\
\hline Staphylococcus aureus, $\mathrm{n}(\%)$ & $71(19 \%)$ & $25(26 \%)$ & .155 & $13(23 \%)$ & $12(30 \%)$ & .487 \\
\hline MRSA, n (\%) & $24(6 \%)$ & $10(10 \%)$ & .187 & $4(7 \%)$ & $6(15 \%)$ & .311 \\
\hline Streptococcus species, $\mathrm{n}(\%)$ & $155(41 \%)$ & $27(28 \%)$ & .019 & $17(30 \%)$ & $10(25 \%)$ & .649 \\
\hline \multicolumn{7}{|l|}{ Comorbidities } \\
\hline Atrial fibrillation, n (\%) & $46(12 \%)$ & $15(16 \%)$ & .396 & $11(20 \%)$ & $4(10 \%)$ & .260 \\
\hline Hemodialysis, $\mathrm{n}(\%)$ & $31(8 \%)$ & $20(21 \%)$ & .001 & $5(9 \%)$ & $15(38 \%)$ & .001 \\
\hline Hypertension, n (\%) & $83(22 \%)$ & $46(48 \%)$ & $<.001$ & $26(46 \%)$ & $20(50 \%)$ & .836 \\
\hline Antiplatelet therapy, n (\%) & $55(14 \%)$ & $24(25 \%)$ & .021 & $14(25 \%)$ & $10(25 \%)$ & 1.000 \\
\hline Anticoagulation therapy, n (\%) & $46(12 \%)$ & $11(11 \%)$ & 1.000 & $8(14 \%)$ & $3(8 \%)$ & .351 \\
\hline \multicolumn{7}{|l|}{ Affected valves } \\
\hline Aortic valve, $\mathrm{n}(\%)$ & $177(47 \%)$ & $49(51 \%)$ & .567 & $30(54 \%)$ & $19(48 \%)$ & .679 \\
\hline Mitral valve involvement, $\mathrm{n}(\%)$ & $265(71 \%)$ & $64(67 \%)$ & .454 & $39(70 \%)$ & $25(63 \%)$ & .514 \\
\hline Double valve, $\mathrm{n}(\%)$ & $70(19 \%)$ & $17(18 \%)$ & .820 & $13(23 \%)$ & $4(10 \%)$ & .111 \\
\hline Prosthetic valve endocarditis, $\mathrm{n}(\%)$ & $59(16 \%)$ & $23(24 \%)$ & .068 & $16(29 \%)$ & $7(18 \%)$ & .204 \\
\hline \multicolumn{7}{|l|}{ Echocardiographic parameters } \\
\hline LVDd, mm & $54(49-60)$ & $50(46-55)$ & .001 & $52(47-57)$ & $49(45-54)$ & .052 \\
\hline LVDs, mm & $34(30-39)$ & $31(28-36)$ & .008 & $32(30-38)$ & $30(27-34)$ & .049 \\
\hline Ejection fraction, $\%$ & $65(59-70)$ & $66(58-73)$ & .710 & $65(58-72)$ & $69(56-74)$ & .242 \\
\hline Systolic tricuspid pressure gradient, $\mathrm{mm} \mathrm{Hg}$ & $30(23-43)$ & $35(26-44)$ & .085 & $35(25-42)$ & $34(28-46)$ & .312 \\
\hline Grade of the affected valve regurgitation & $3.1 \pm 1.1$ & $2.7 \pm 1.2$ & .005 & $2.6 \pm 1.2$ & $2.8 \pm 1.1$ & .598 \\
\hline Maximum length of vegetation, $\mathrm{mm}$ & $12(9-16)$ & $13(10-19)$ & .032 & $13(9-16)$ & $16(10-21)$ & .060 \\
\hline \multicolumn{7}{|l|}{ Preoperative hemodynamics } \\
\hline Symptomatic heart failure, $\mathrm{n}(\%)$ & $185(49 \%)$ & $49(51 \%)$ & .783 & $28(50 \%)$ & $21(53 \%)$ & .809 \\
\hline Inotropic support, $\mathrm{n}(\%)$ & $91(24 \%)$ & $24(25 \%)$ & .895 & $13(23 \%)$ & $11(28 \%)$ & .634 \\
\hline Intubation, $\mathrm{n}(\%)$ & $44(12 \%)$ & $11(11 \%)$ & .934 & $7(13 \%)$ & $4(10 \%)$ & .705 \\
\hline \multicolumn{7}{|l|}{ Embolism } \\
\hline Extremities, n (\%) & $25(7 \%)$ & $4(4 \%)$ & .478 & $4(7 \%)$ & $0(0 \%)$ & .138 \\
\hline Spleen, n $(\%)$ & $48(12 \%)$ & $12(13 \%)$ & .930 & $8(14 \%)$ & $4(10 \%)$ & .756 \\
\hline Kidney, n (\%) & $27(7 \%)$ & $4(4 \%)$ & .361 & $3(5 \%)$ & $1(3 \%)$ & .638 \\
\hline Symptomatic stroke, n (\%) & $92(25 \%)$ & $36(38 \%)$ & .015 & $25(45 \%)$ & $11(28 \%)$ & .084 \\
\hline Ischemic stroke, n (\%) & $121(32 \%)$ & $47(49 \%)$ & .003 & $28(50 \%)$ & $19(48 \%)$ & .809 \\
\hline Hemorrhagic stroke, n (\%) & $43(12 \%)$ & $11(11 \%)$ & .992 & $8(14 \%)$ & $3(8 \%)$ & .351 \\
\hline \multicolumn{7}{|l|}{ Laboratory valuables at diagnosis } \\
\hline White blood cell counts, $\times 1000 / \mu \mathrm{L}$ & $10.0(7.6-13.4)$ & $11.8(8.4-15.2)$ & .035 & $11.1(8.4-13.9)$ & $13.3(7.8-16.1)$ & .135 \\
\hline C-reactive protein, $\mathrm{mg} / \mathrm{dL}$ & $6.5(3.6-10.9)$ & $7.8(4.5-12.2)$ & .073 & $7.1(5.3-12.4)$ & $8.3(4.2-10.9)$ & .945 \\
\hline Hemoglobin, g/dL & $10.4(9.0-11.9)$ & $10.3(8.7-11.4)$ & .405 & $10.7(9.5-11.5)$ & $9.7(8.4-11.1)$ & .059 \\
\hline Platelet counts, $\times 1000 / \mu \mathrm{L}$ & $188(117-252)$ & $168(113-230)$ & .110 & $173(100-228)$ & $166(114-232)$ & .331 \\
\hline Blood urea nitrogen, $\mathrm{mg} / \mathrm{dL}$ & $17(12-28)$ & $25(15-42)$ & .003 & $20(12-32)$ & $34(19-53)$ & .009 \\
\hline Creatinine, $\mathrm{mg} / \mathrm{dL}$ & $0.86(0.70-1.20)$ & $1.13(0.85-2.19)$ & .004 & $0.95(0.81-1.88)$ & $1.57(0.89-5.60)$ & .007 \\
\hline estimated GFR, $\mathrm{mL} / \mathrm{min} / 1.73 \mathrm{~m}^{2}$ & $90(60-114)$ & $59(27-92)$ & $<.001$ & $80(37-95)$ & $40(10-67)$ & .010 \\
\hline Total bilirubin, $\mathrm{mg} / \mathrm{dL}$ & $0.7(0.5-1.0)$ & $0.7(0.5-1.1)$ & .421 & $0.8(0.6-1.1)$ & $0.7(0.4-0.9)$ & .467 \\
\hline Lactate dehydrogenase, IU/L & $294(236-412)$ & $305(259-383)$ & .849 & $320(238-411)$ & $305(280-384)$ & .568 \\
\hline Total protein, $\mathrm{mg} / \mathrm{dL}$ & $6.5(5.9-7.1)$ & $6.3(5.7-6.9)$ & .022 & $6.4(5.7-6.8)$ & $6.3(5.2-6.9)$ & .261 \\
\hline Albumin, mg/dL & $2.95 \pm 0.58$ & $2.76 \pm 0.56$ & .014 & $2.79 \pm 0.55$ & $2.72 \pm 0.57$ & .599 \\
\hline
\end{tabular}


TABLE 1. Continued

\begin{tabular}{|c|c|c|c|c|c|c|}
\hline & Diabetes mellitus (-) & Diabetes mellitus $(+)$ & & Insulin (-) & Insulin (+) & \\
\hline & $n=374$ & $\mathrm{n}=96$ & $P$ value & $\mathrm{n}=\mathbf{5 6}$ & $\mathrm{n}=\mathbf{4 0}$ & $P$ value \\
\hline International normalization ratio & $1.20(1.11-1.36)$ & $1.20(1.10-1.48)$ & .578 & $1.20(1.13-1.60)$ & $1.15(1.05-1.35)$ & .112 \\
\hline Duration between diagnosis and surgery, $\mathrm{d}$ & $10(2-26)$ & $7(1-21)$ & .230 & $7(2-18)$ & $6(1-28)$ & .451 \\
\hline \multicolumn{7}{|l|}{ Laboratory valuables just before surgery } \\
\hline White blood cell counts, $\times 1000 / \mu \mathrm{L}$ & $8.1(5.8-11.3)$ & $8.8(6.4-12.6)$ & .119 & $9.0(6.5-12.6)$ & $8.7(6.0-14.0)$ & .708 \\
\hline C-reactive protein, $\mathrm{mg} / \mathrm{dL}$ & $3.2(0.8-7.2)$ & $4.5(1.5-10.3)$ & .006 & $5.2(1.6-10.4)$ & $3.7(1.2-9.6)$ & .646 \\
\hline Hemoglobin, g/dL & $10.2(9.1-11.7)$ & $9.9(8.6-11.3)$ & .239 & $10.3(9.3-11.7)$ & $8.7(8.2-10.9)$ & .017 \\
\hline Platelet counts, $\times 1000 / \mu \mathrm{L}$ & $193(123-248)$ & $159(106-233)$ & .043 & $159(102-235)$ & $166(115-232)$ & .924 \\
\hline Blood urea nitrogen, $\mathrm{mg} / \mathrm{dL}$ & $17(12-27)$ & $20(14-39)$ & .006 & $17(12-37)$ & $28(14-58)$ & .037 \\
\hline Creatinine, $\mathrm{mg} / \mathrm{dL}$ & $0.91(0.70-1.26)$ & $1.18(0.82-1.97)$ & .001 & $0.98(0.80-1.86)$ & $1.40(0.90-5.25)$ & .043 \\
\hline Estimated GFR, $\mathrm{mL} / \mathrm{min} / 1.73 \mathrm{~m}^{2}$ & $84(58-111)$ & $57(34-90)$ & $<.001$ & $74(36-90)$ & $47(10-71)$ & .022 \\
\hline Total bilirubin, $\mathrm{mg} / \mathrm{dL}$ & $0.6(0.4-0.9)$ & $0.6(0.4-1.0)$ & .541 & $0.7(0.5-1.0)$ & $0.5(0.4-0.7)$ & .037 \\
\hline Lactate dehydrogenase, IU/L & $298(229-408)$ & $309(262-371)$ & .522 & $308(260-423)$ & $310(269-355)$ & .882 \\
\hline International normalization ratio & $1.17(1.10-1.32)$ & $1.20(1.10-1.34)$ & .797 & $1.20(1.14-1.40)$ & $1.13(1.05-1.26)$ & .031 \\
\hline
\end{tabular}

\section{Statistical Analysis}

Statistical analysis was performed with SPSS version 23 (SAS Institute Inc, Cary, NC). Categorical variables were presented as percentages, and continuous data as means, standard deviations, or medians (interquartile range) after testing for normality using the Shapiro-Wilk W test. The comparisons between the 2 groups were performed with the $\chi^{2}$ test for categorical variables. Welch $t$ test, or Mann-Whitney $U$ test for continuous variables, as appropriate. All $P$ values for statistical analyses were 2-tailed, and $P<.05$ indicated a statistically significant difference.

Overall survival and freedom from recurrence of endocarditis rates were estimated with Kaplan-Meier curves and compared between the groups with a log-rank test. The multiple regression model was applied to identify the risk factors for in-hospital mortality after the valve surgery. Cox regression hazard models were applied to identify the risk factors for overall mortality, mortality after the first discharge, and recurrence of endocarditis. All the valuables enrolled in the analysis are listed in Table E2. To summarize, baseline characteristics, preoperative valuables, comorbidities, or complications were enrolled for risk analysis of in-hospital mortality or overall mortality rate. Similarly, baseline characteristics, preoperative and postoperative complications, and operative and postoperative valuables were enrolled for the risk analysis of mortality after the first discharge and recurrence of endocarditis. The univariate analysis initially was applied, then the factors with $P<.05$ were considered for inclusion in the multivariate multiple regression or Cox hazard model to identify the risk factors.

For further comparison of the overall survival and recurrence of endocarditis in patients with and without DM, backgrounds of 2 groups were adjusted by propensity score matching. The propensity score was obtained by multivariate logistic regression. The applied variables that have been reported as independent risk for mortality (age, heart failure, prosthetic valve endocarditis, preoperative hemodialysis, and Staphylococcus aureus infection) were selected in this study. We performed a 1:2 nearest-available matching algorithm with a 0.1 caliper, then 150 patients without DM and 75 patients with DM were extracted depending on the propensity score matching model.

\section{RESULTS}

During this study period, 470 patients underwent valve surgery for left-sided active IE. Of them, $96(20 \%)$ patients had concomitant DM. We compared the preoperative valuables and clinical results between patients with DM $(\mathrm{n}=96)$ and patients without DM $(\mathrm{n}=374)$. In 96 patients with DM, 40 (42\%) patients required chronic subcutaneous insulin injection for DM treatment. Baseline and preoperative characteristics of the patients are summarized in Table 1. Patients with DM were significantly older and had larger body mass index than patients without DM. Staphylococcus species were significantly more prevalent and streptococcus species were less prevalent in patients with DM. The prevalence of chronic hemodialysis, hypertension, and antiplatelet use was significantly greater in patients with DM; particularly, chronic hemodialysis was prevalent in patients with insulin. No statistical difference in the affected valves and the proportion of prosthetic valve endocarditis was found between the groups.

Although the presence of symptomatic heart failure, requirement of inotropic support, or intubation was similar, the dimension of the left ventricle was significantly smaller in patients with DM, particularly in patients with insulin, whereas there was no statistical differences regarding the left ventricular (LV) ejection fraction among the groups. In addition, patients with DM had a trend for greater systolic tricuspid pressure gradient, although they had a lower grade of regurgitation of the affected valve. The vegetation size was significantly larger in patients with DM. Acute cerebral infarction was more prevalent in patients with DM. As for preoperative laboratory valuables (both at the time of diagnosis and just before the valve surgery), the inflammation levels were greater and the renal function was worse in patients with DM, especially in patients with insulin, whereas the liver function was similar among the 2 groups. The median duration from endocarditis diagnosis to valve surgery was 10 (2-26) days in patients without $\mathrm{DM}$ and $7(1-21)$ days in patients with $\mathrm{DM}(P=.230)$.

The operative and postoperative outcomes of patients are detailed in Table 2. Among all patients without DM, 
TABLE 2. Operative results

\begin{tabular}{|c|c|c|c|c|c|c|}
\hline & $\frac{\text { Diabetes mellitus (-) }}{\mathrm{n}=\mathbf{3 7 4}}$ & $\frac{\text { Diabetes mellitus }(+)}{\mathbf{n}=96}$ & $P$ value & $\begin{array}{c}\text { Insulin (-) } \\
\mathbf{n}=\mathbf{5 6}\end{array}$ & $\begin{array}{c}\text { Insulin (+) } \\
\mathbf{n}=\mathbf{4 0}\end{array}$ & $P$ value \\
\hline Aortic valve $(\mathrm{n}=226)$ & $\mathrm{n}=177$ & $\mathrm{n}=49$ & & $\mathrm{n}=30$ & $\mathrm{n}=19$ & \\
\hline Valve repair, $\mathrm{n}(\%)$ & $1(1 \%)$ & $0(0 \%)$ & 1.000 & $0(0 \%)$ & $0(0 \%)$ & 1.000 \\
\hline Valve replacement, n (\%) & $176(99 \%)$ & $49(100 \%)$ & & $30(100 \%)$ & $19(100 \%)$ & \\
\hline Bioprosthetic valve, $\mathrm{n}(\%)$ & $141(80 \%)$ & $46(94 \%)$ & .029 & $30(100 \%)$ & $16(84 \%)$ & .053 \\
\hline Mechanical valve, $\mathrm{n}(\%)$ & $35(20 \%)$ & $3(6 \%)$ & & $0(0 \%)$ & $3(16 \%)$ & \\
\hline Aortic root surgery, n (\%) & $17(10 \%)$ & $10(20 \%)$ & .048 & $7(23 \%)$ & $3(16 \%)$ & .720 \\
\hline Mitral valve $(\mathrm{n}=329)$ & $\mathrm{n}=265$ & $\mathrm{n}=64$ & & $\mathrm{n}=39$ & $\mathrm{n}=25$ & \\
\hline Valve repair, n (\%) & $114(43 \%)$ & $27(42 \%)$ & .904 & $17(44 \%)$ & $10(40 \%)$ & .776 \\
\hline Valve replacement, n (\%) & $151(57 \%)$ & $37(58 \%)$ & & $22(56 \%)$ & $15(60 \%)$ & \\
\hline Bioprosthetic valve, $\mathrm{n}(\%)$ & $100(66 \%)$ & $29(78 \%)$ & .143 & $17(77 \%)$ & $12(80 \%)$ & 1.000 \\
\hline Mechanical valve, $\mathrm{n}(\%)$ & $51(34 \%)$ & $8(22 \%)$ & & $5(23 \%)$ & $3(20 \%)$ & \\
\hline Requirement of CABG, $\mathrm{n}(\%)$ & $13(3 \%)$ & $12(13 \%)$ & .002 & $8(14 \%)$ & $4(10 \%)$ & .756 \\
\hline Requirement of double valve surgery, $\mathrm{n}(\%)$ & $68(18 \%)$ & $17(18 \%)$ & .819 & $13(23 \%)$ & $4(10 \%)$ & .111 \\
\hline Requirement of annular reconstruction, $\mathrm{n}(\%)$ & $61(16 \%)$ & $26(27 \%)$ & .019 & $17(30 \%)$ & $9(23 \%)$ & .390 \\
\hline \multicolumn{7}{|l|}{ Operative time and transfusion } \\
\hline Operative time, $\min$ & $311(260-399)$ & $335(261-485)$ & .028 & $340(265-578)$ & $329(255-407)$ & .043 \\
\hline Cardiopulmonary bypass time, $\min$ & $166(130-225)$ & $169(134-259)$ & .076 & $191(138-267)$ & $147(122-217)$ & .051 \\
\hline Aortic clamp time, min & $124(92-167)$ & $130(92-199)$ & .046 & $148(94-204)$ & $119(90-182)$ & .198 \\
\hline Platelet transfusion, units & $0(0-20)$ & $10(0-20)$ & .019 & $10(0-30)$ & $20(3-20)$ & .704 \\
\hline \multicolumn{7}{|l|}{ Complications } \\
\hline Requirement of ECMO, n (\%) & $7(2 \%)$ & $6(6 \%)$ & .035 & $5(9 \%)$ & $1(3 \%)$ & .396 \\
\hline Neurologic deterioration, $\mathrm{n}(\%)$ & $19(5 \%)$ & $4(4 \%)$ & 1.000 & $2(4 \%)$ & $2(5 \%)$ & 1.000 \\
\hline Mediastinitis, n (\%) & $4(1 \%)$ & $4(4 \%)$ & .059 & $1(2 \%)$ & $3(8 \%)$ & .305 \\
\hline Requirement of CVVHD, n (\%) & $42(11 \%)$ & $26(27 \%)$ & $<.001$ & $16(29 \%)$ & $10(25 \%)$ & .697 \\
\hline Complete AV block, $\mathrm{n}(\%)$ & $8(2 \%)$ & $2(2 \%)$ & 1.000 & $0(0 \%)$ & $2(5 \%)$ & .171 \\
\hline Intubation duration, $\mathrm{d}$ & $1(0-2)$ & $2(1-4)$ & .010 & $2(1-5)$ & $2(1-4)$ & .916 \\
\hline Duration of intravenous antibiotics, $d$ & $28(18-37)$ & $35(26-42)$ & .005 & $36(25-43)$ & $34(27-42)$ & .477 \\
\hline Hospital stay, d & $35(23-52)$ & $46(31-92)$ & .007 & $43(27-75)$ & $61(32-99)$ & .475 \\
\hline 30-d mortality, n (\%) & $16(4 \%)$ & $7(7 \%)$ & .236 & $6(11 \%)$ & $1(3 \%)$ & .234 \\
\hline Hospital mortality, n (\%) & $30(8 \%)$ & $12(13 \%)$ & .187 & $8(14 \%)$ & $4(10 \%)$ & .756 \\
\hline \multicolumn{7}{|l|}{ Reason of in-hospital death } \\
\hline Heart failure, $\mathrm{n}(\%)$ & $9(2 \%)$ & $3(3 \%)$ & .717 & $3(5 \%)$ & $0(0 \%)$ & .263 \\
\hline Organ failure, $\mathrm{n}(\%)$ & $14(4 \%)$ & $6(6 \%)$ & .300 & $4(7 \%)$ & $2(5 \%)$ & 1.000 \\
\hline Refractory infection, n (\%) & $9(2 \%)$ & $5(5 \%)$ & .179 & $3(5 \%)$ & $2(5 \%)$ & 1.000 \\
\hline Cerebrovascular accident, $\mathrm{n}(\%)$ & $5(1 \%)$ & $2(2 \%)$ & .635 & $1(2 \%)$ & $1(3 \%)$ & 1.000 \\
\hline
\end{tabular}

$C A B G$, Coronary artery bypass grafting; $E C M O$, extracorporeal membrane oxygenation; $C V V H D$, continuous veno-venous hemodialysis; $A V$, atrioventricular.

$177(47 \%)$ had aortic valve surgery and $265(71 \%)$ had mitral valve surgery, including $68(18 \%)$ patients with double valve surgery. In contrast, among patients with DM, $49(51 \%)$ had aortic valve surgery and $64(67 \%)$ had mitral valve surgery, including $17(18 \%)$ with double valve surgery. No differences in the prevalence of the mitral valve repair were found between the 2 groups. In addition, a greater proportion of patients with DM required concomitant coronary artery bypass graft or annular reconstruction (patch reconstruction or aortic root surgery) for severe perivalvular abscess. Longer operative time and aortic crossclamp time was seen in patients with DM, in whom more platelet products were necessary. Postoperative complications are also detailed in Table 2. The need for of extracorporeal membranous oxygenation and continuous veno-venous hemodialysis (CVVHD) was more prevalent in patients with DM. Moreover, the duration of intubation, intravenous antibiotic therapy, and hospital stay was significantly longer in these patients. In-hospital mortality was seen in $30(8 \%)$ patients of the non-DM group and in $12(13 \%)$ of the DM group $(P=.187)$. No differences regarding the cause of in-hospital mortality were found between the 2 groups.

We compared the change of pre- and postoperative inflammation levels and end-organ function between the DM and non-DM groups (Table E3). Although both white 

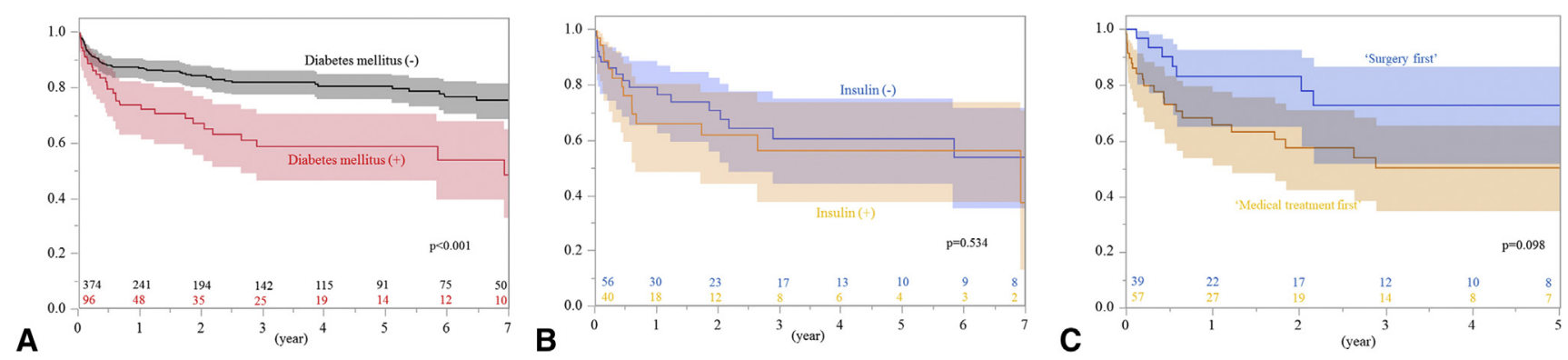

FIGURE 1. The Kaplan-Meier analysis of the overall survival and its $95 \%$ confidence interval. A, Patients without DM (black line) and patients with DM (red line). B, Patients without insulin use (blue line) and patients with insulin use (orange line). C, The overall survival in 96 patients with DM according to the initial intention-to-treat plan. Patients with "surgery first" (blue line) and patients with "medical first" (orange line).

blood cell counts and serum C-reactive protein levels steadily decreased during the postoperative periods in both groups, there was a trend of greater inflammation levels in patients with DM. The renal function was significantly worse in patients with DM throughout all treatment periods; however, the renal parameters did not significantly change in time during the studied period in both groups.

The multivariate analysis of the preoperative risk factors for in-hospital mortality is shown in Table E4. The multivariate analysis revealed older age, presence of heart failure, prosthetic valve endocarditis, and lower platelet counts were independent risk factors for in-hospital mortality. The presence of diabetes was not a risk factor for in-hospital mortality.

The overall survival rate at 1,3 , and 5 years was $87 \%$, $82 \%$, and $81 \%$, respectively, in the non-DM group, and $72 \%, 59 \%$, and $59 \%$, respectively in the DM group (Figure 1, A, $P<.001$ ). There was no differences about overall survival between patients with and without insulin. (Figure 1, B). When we compared overall survival between
2 initial intention-to-treat plans in the DM group, there was a trend of better prognosis if patients had "surgery first" as an initial intention-to-treat plan compared with "medical treatment first" (Figure 1, $C$ ). The survival rate after the first discharge at 1,3 , and 5 years was $96 \%, 90 \%$, and $88 \%$, respectively in the non-DM group, and $84 \%, 68 \%$, and $68 \%$, respectively in the DM group (Figure E1, A, $P<.001)$. Insulin use did not make an impact on survival after the first discharge (Figure E1, $B$ ). These worse survival rates in the DM group were seen especially in patients with aortic valve involvement rather than those with mitral valve involvement (Figure E2, $A$ and $B$ ). Cox hazard analysis of the preoperative risk factors for overall mortality are summarized in Table 3. The multivariate analysis revealed that older age, DM, chronic hemodialysis, $S$ aureus infection, double valve involvement, prosthetic valve endocarditis, and lower platelet counts were independent risk factors for overall mortality. In addition, the risk analysis about the baseline characteristics and operative and postoperative parameters for the overall mortality after the first discharge are shown in Table E5. The multivariate

TABLE 3. Preoperative risk factors for overall mortality

\begin{tabular}{|c|c|c|c|c|}
\hline & \multicolumn{2}{|c|}{ Univariate } & \multicolumn{2}{|c|}{ Multivariate } \\
\hline & $\overline{\text { Hazard ratio }(95 \% \mathrm{CI})}$ & $P$ value & Hazard ratio $(95 \% \mathrm{CI})$ & $P$ value \\
\hline Age, y & $1.06(1.03-1.07)$ & $<.001$ & $1.04(1.02-1.07)$ & $<.001$ \\
\hline Diabetes mellitus & $2.25(1.45-3.42)$ & $<.001$ & $1.65(1.04-2.57)$ & .034 \\
\hline Chronic hemodialysis & $2.85(1.73-4.50)$ & $<.001$ & $2.36(1.17-4.70)$ & .017 \\
\hline Heart failure & $1.94(1.29-2.95)$ & .001 & $1.44(0.93-2.29)$ & .106 \\
\hline Staphylococcus aureus infection & $2.11(1.35-3.23)$ & .002 & $2.09(1.22-3.49)$ & .008 \\
\hline Double valve involvement & $2.13(1.30-3.34)$ & .003 & $1.83(1.09-2.97)$ & .024 \\
\hline Prosthetic valve endocarditis & $2.28(1.43-3.40)$ & .001 & $2.26(1.37-3.67)$ & .002 \\
\hline \multicolumn{5}{|c|}{ Laboratory valuables just before surgery } \\
\hline Platelet counts, $\times 1000 / \mu \mathrm{L}$ & $0.92(0.90-0.95)$ & $<.001$ & $0.95(0.92-0.97)$ & .003 \\
\hline C-reactive protein, $\mathrm{mg} / \mathrm{dL}$ & $1.03(1.00-1.05)$ & .031 & $0.99(0.96-1.02)$ & .981 \\
\hline $\mathrm{eGFR}, \mathrm{mL} / \mathrm{min} / 1.73 \mathrm{~m}^{2}$ & $0.99(0.98-0.99)$ & $<.001$ & $1.00(0.99-1.01)$ & .338 \\
\hline \multicolumn{5}{|l|}{ Echocardiographic parameters } \\
\hline LVEF, \% & $0.98(0.96-1.00)$ & .018 & $0.98(0.96-1.00)$ & .068 \\
\hline
\end{tabular}

$C I$, Confidence interval; $e G F R$, estimated glomerular filtration rate; $L V E F$, left ventricle ejection fraction. 

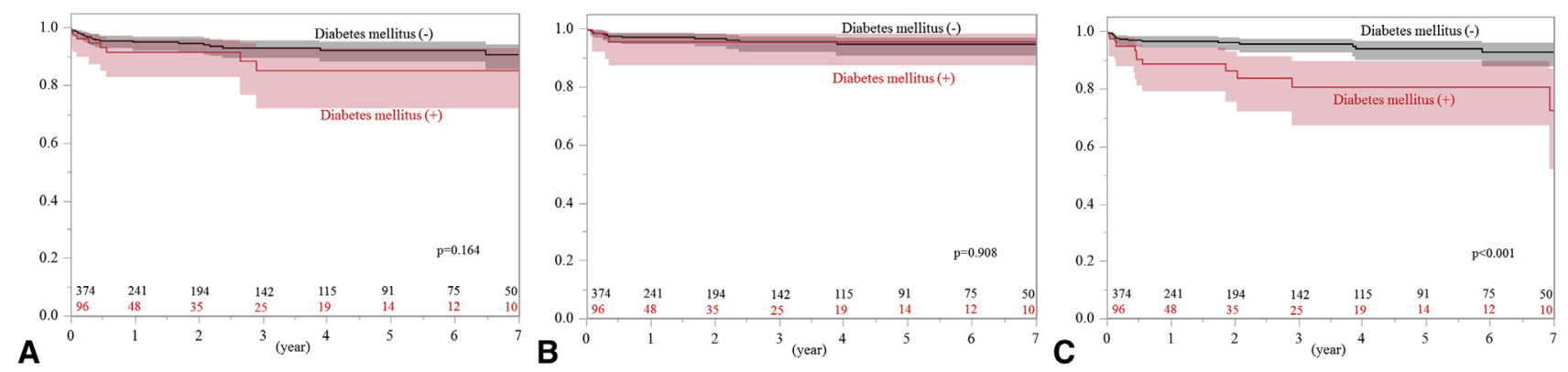

FIGURE 2. The Kaplan-Meier analysis of the free from A, cardiovascular-related death; B, cerebrovascular accident-related death; and C, infection-related death.

analysis revealed that older age, presence of DM, greater C-reactive protein level at 2 weeks after surgery, and low ejection fraction were independent risk factors for overall mortality after the first discharge. Because the presence of chronic hemodialysis, $S$ aureus endocarditis, and prosthetic valve endocarditis were the independent risk factors for overall mortality as well as DM, we further analyzed the overall mortality according to the stratification about presence of DM and these parameters (Figure E3, $A-C$ ). When we analyzed overall mortality in the propensity matched cohort, the overall survival was still significantly worse in patients with $\mathrm{DM}(P=.008$, Figure $\mathrm{E} 4, A)$.

We further subdivided the cause of death into several reasons and compared them between the 2 groups. The rates of free from cardiovascular-related death, CVA-related death, and infection-related death are shown in Figure 2, $A$ and $C$. Although there was no statistical difference about cardiovascular-related death and CVA-related death between the 2 groups, the free from infection-related death was significantly lower in patients with DM $(P<.001$, hazard ratio 3.74 [1.78-7.71]).

During the follow-up period, 21 patients developed recurrence of endocarditis. The rate of freedom from recurrence of endocarditis at 1,3 , and 5 years was $98 \%$, $97 \%$, and $95 \%$, respectively in the non-DM group and
$89 \%, 83 \%$, and $78 \%$, respectively, in the DM group (Figure 3, $A, P<.001$ ). There were no statistical differences about recurrence of endocarditis between patients with and without insulin use (Figure 3, B). The Cox hazard risk analysis of the baseline, operative, and postoperative risk factors for recurrence of endocarditis are shown in Table 4. Univariate analysis showed that the presence of $\mathrm{DM}$, prosthetic valve endocarditis, perivalvular abscess, and requirement of postoperative CVVHD were risk factors for the recurrence of endocarditis. Multivariate risk analysis revealed that the presence of DM was the only independent risk factor for the recurrence of endocarditis (hazard ratio 3.74 [1.45-9.54], $P=.007$ ). When we analyzed in the propensity matched cohort, the rate of freedom from recurrence of endocarditis was also significantly worse in patients with $\mathrm{DM}(P=.004$, Figure $\mathrm{E} 4, B)$.

\section{DISCUSSION}

In the present study, patients with DM had a more severe preoperative condition than patients without DM. Staphylococcus species, which has been reported as a risk factor for mortality, ${ }^{4,5}$ was more common in patients with DM. There have been controversies about relationship between DM and heart failure in patients with IE. ${ }^{10,12,16}$ In the present study, although the presence
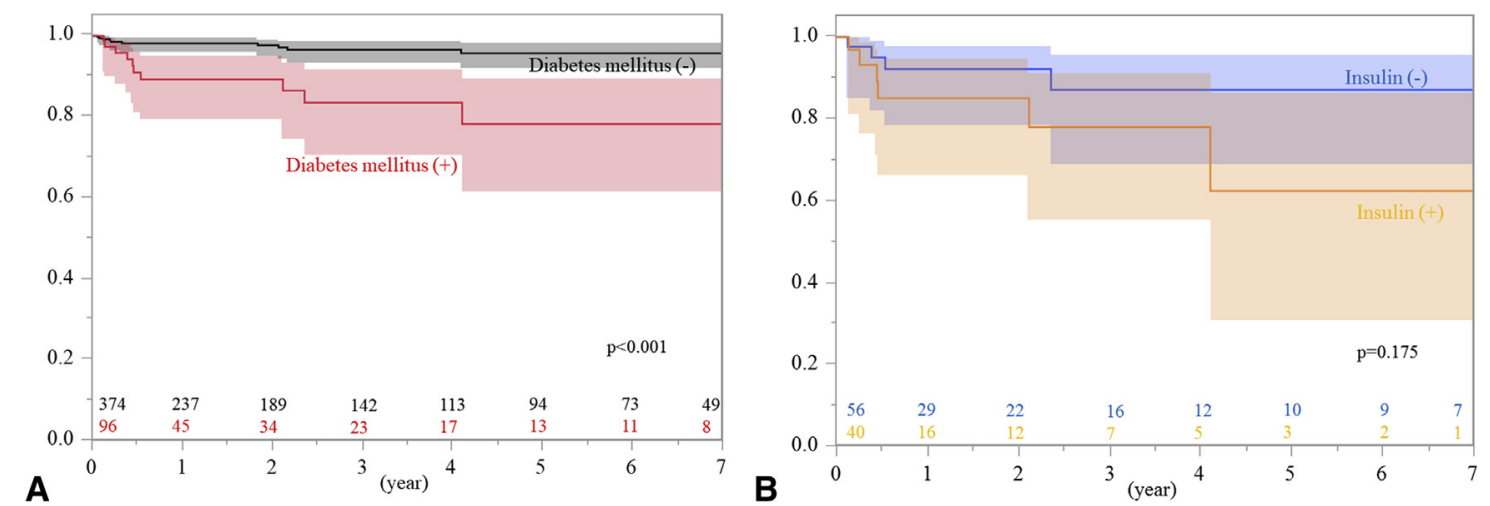

FIGURE 3. The Kaplan-Meier analysis of the rate of freedom from recurrence of endocarditis. A, Patients without DM (black line) and patients with DM (red line). B, Patients without insulin use (blue line) and patients with insulin use (orange line). 
TABLE 4. Risk factors for recurrence of endocarditis

\begin{tabular}{|c|c|c|c|c|}
\hline & \multicolumn{2}{|c|}{ Univariate } & \multicolumn{2}{|c|}{ Multivariate } \\
\hline & Hazard ratio $(95 \% \mathrm{CI})$ & $P$ value & Hazard ratio $(95 \%$ CI $)$ & $P$ value \\
\hline Diabetes mellitus & $4.50(1.78-11.2)$ & .002 & $3.74(1.45-9.54)$ & .007 \\
\hline Prosthetic valve endocarditis & $2.89(1.08-7.21)$ & .036 & $2.06(0.64-6.23)$ & .219 \\
\hline Perivalvular abscess & $3.03(1.13-7.53)$ & .030 & $2.04(0.65-5.98)$ & .215 \\
\hline Need of postoperative CVVHD & $4.68(1.48-12.6)$ & .011 & $3.12(0.96-8.81)$ & .059 \\
\hline
\end{tabular}

$C I$, Confidence interval; $C V V H D$, continuous veno-venous hemodialysis.

of symptomatic heart failure and the LV ejection fraction were similar between the groups and the degree of regurgitation of the affected valve was lower in patients with DM, they had smaller LV dimensions and greater systolic tricuspid pressure gradients. These results could be interpreted by the LV diastolic dysfunction in patients with DM. ${ }^{17}$ Furthermore, in the present study, $20 \%$ of patients with DM received chronic hemodialysis, and median eGFR was significantly lower in patients with DM. Renal dysfunction has been reported to be one of the risk factors for mortality in patients with IE. ${ }^{5,10,18}$ It is reasonable that some severe preoperative conditions predispose patients with DM to several postoperative complications (eg, mediastinitis or the requirement of CVVHD or extracorporeal membranous oxygenation) and longer intravenous antibiotic therapy and hospital stay even, although there was no statistical significance for in-hospital mortality.

Several reports evaluated the negative impact of DM on in-hospital mortality or short-term mortality, although these previous reports were composed of many patients who did not undergo valve surgery in the acute phase of IE. 1,3,4,10,16 Furthermore, importantly, patients with DM were more likely to avoid valve surgery because of the poorer health condition at IE diagnosis. ${ }^{2}$ Therefore, studies that analyzed the impact of DM on mortality rates after valve surgery are very limited. Gaca and colleagues ${ }^{19}$ reported in a study based on the Society of Thoracic Surgeons database that DM (both insulin dependent and insulin independent) was one of the predictors of 30-day mortality after valve surgery for IE, although the clinical results after the discharge was unknown. Our study first evaluated that patients with DM had worse survival rate even after once they survived valve surgery, because the infection related-death was more prevalent in them even though the prevalence of CVA- or cardiovascular-related death was similar between patients with DM and without DM. This similarity of cardiovascular-related and CVA-related mortality in patients with DM was probably because cardiac function was relatively preserved with their median ejection fraction of $66 \%$, and the cause of CVA in IE patients (eg, rupture of mycotic aneurysm, embolism of vegetation) is fundamentally different from CVA in general DM population. ${ }^{20,21}$ To the best of our knowledge, we revealed for the first time that DM does not affect cardiovascular-related or CVA-related mortality in short- and mid-term follow-up period.

The recurrence of IE is one of the main concerns in patients who undergo valve surgery for active IE. Although the greater infection-related mortality rates in patients with DM may be related to the adverse effects of hyperglycemia on immune function in general population, ${ }^{22,23}$ a limited number of studies investigated the impact of DM on IE recurrence. Several previous studies have evaluated that the freedom from IE recurrence after valve surgery was between $80 \%$ and $90 \%$ at 5 years, although the predictors of IE recurrence were not analyzed. ${ }^{18,24,25}$ Renzulli and colleagues $^{26}$ reported that not DM, but prosthetic valve endocarditis, positive valve culture, and persistent fever at seventh postoperative day were the predictors of IE recurrence. In the present study, the presence of DM was the only independent predictor of IE recurrence, and approximately $10 \%$ of patients with DM developed IE recurrence during the first year. Although no guidelines and studies about the efficacy of life-long prophylactic therapy for prevention of recurrence after valve surgery for IE are available, oral prophylactic antibiotics therapy after the discharge might be considered in patients with DM.

The present study has several limitations. First, the present study was a retrospective multicenter study with a limited number of patients in each hospital. Although the basic strategy was managed according to the guideline, it is possible that there was a difference in treatment strategy (eg, timing of surgery, antibiotics duration). Second, though the analysis about the impact of insulin dependence on mortality in patients with IE was evaluated, the total number of patients with insulin was limited; therefore, further evaluation about the impact of insulin is demanded. In addition, the impact of diabetes control on outcome could not be evaluated. Third, the data about the oral antibiotic therapy after the discharge could not be collected. Finally, we only collected data about the incidence of death and its cause, and we could not collect data about each adverse event after the first discharge. As for IE recurrence, there was possible that different bacterial species accidentally 
caused de novo endocarditis after valve surgery, although majority of IE recurrence patients had the same species with the previous IE.

In conclusion, patients with DM who have active IE have a more severe condition before valve surgery than patients without DM. The short- and mid-term prognosis is poor in patients with DM who have IE because of the relatively greater prevalence of infection-related death and the relatively greater rate of IE recurrence.

\section{Conflicts of Interest Statement}

Authors have nothing to disclose with regard to commercial support.

We thank physicians who prepared medical charts for us and who made telephone calls for the follow-up of patients in each hospital.

\section{References}

1. Murdoch DR, Corey GR, Hoen B, Miro JM, Fowler VG Jr, Bayer AS, et al. Clinical presentation, etiology, and outcome of infective endocarditis in the 21st century: the International Collaboration on Endocarditis-Prospective Cohort Study. Arch Intern Med. 2009;169:463-73.

2. Chu VH, Park LP, Athan E, Delahaye F, Freiberger T, Lamas C, et al. Association between surgical indications, operative risk, and clinical outcome in infective endocarditis: a prospective study from the International Collaboration on Endocarditis. Circulation. 2015;131:131-40.

3. Park LP, Chu VH, Peterson G, Skoutelis A, Lejko-Zupa T, Bouza E, et al. Validated risk score for predicting 6-month mortality in infective endocarditis. J Am Heart Assoc. 2016;5:e003016.

4. Chu VH, Cabell CH, Benjamin DK Jr, Kuniholm EF, Fowler VG Jr, Engemann J, et al. Early predictors of in-hospital death in infective endocarditis. Circulation. 2004; 109:1745-9.

5. Pericart L, Fauchier L, Bourguignon T, Bernard L, Angoulvant D, Delahaye F, et al. Long-term outcome and valve surgery for infective endocarditis in the systematic analysis of a community study. Ann Thorac Surg. 2016;102:496-504.

6. Lopez-de-Andres A, de Miguel-Diez J, Jimenez-Trujillo I, Hernandez-Barrera V, de Miguel-Yanes JM, Mendez-Bailon M, et al. Hospitalisation with communityacquired pneumonia among patients with type 2 diabetes: an observational population-based study in Spain from 2004 to 2013. BMJ Open. 2017;7:e013097.

7. Shah BR, Hux JE. Quantifying the risk of infectious diseases for people with diabetes. Diabetes Care. 2003:26:510-3.

8. Movahed MR, Hashemzadeh M, Jamal MM. Increased prevalence of infectious endocarditis in patients with type II diabetes mellitus. J Diabetes Complications. 2007;21:403-6

9. Chirillo F, Bacchion F, Pedrocco A, Scotton P, De Leo A, Rocco F, et al. Infective endocarditis in patients with diabetes mellitus. J Heart Valve Dis. 2010;19:312-20.
10. Duval X, Alla F, Doco-Lecompte T, Le Moing V, Delahaye F, Mainardi JL, et al Diabetes mellitus and infective endocarditis: the insulin factor in patien morbidity and mortality. Eur Heart J. 2007;28:59-64.

11. Leither MD, Shroff GR, Ding S, Gilbertson DT, Herzog CA. Long-term survival of dialysis patients with bacterial endocarditis undergoing valvular replacement surgery in the United States. Circulation. 2013;128:344-51.

12. Olmos C, Vilacosta I, Fernandez C, Lopez J, Sarria C, Ferrera C, et al Contemporary epidemiology and prognosis of septic shock in infective endocarditis. Eur Heart J. 2013;34:1999-2006.

13. Yoshioka D, Toda K, Yokoyama JY, Matsuura R, Miyagawa S, Shirakawa Y, et al Recent surgical results for active endocarditis complicated with perivalvular abscess. Circ J. June 8, 2017 [Epub ahead of print].

14. Baddour LM, Wilson WR, Bayer AS, Fowler VG Jr, Tleyjeh IM, Rybak MJ, et al Infective endocarditis in adults: diagnosis, antimicrobial therapy, and management of complications: a scientific statement for healthcare professionals from the American Heart Association. Circulation. 2015;132:1435-86.

15. Li JS, Sexton DJ, Mick N, Nettles R, Fowler VG Jr, Ryan T, et al. Proposed modifications to the Duke criteria for the diagnosis of infective endocarditis. Clin Infect Dis. 2000;30:633-8.

16. Kiefer T, Park L, Tribouilloy C, Cortes C, Casillo R, Chu V, et al Association between valvular surgery and mortality among patients with infective endocarditis complicated by heart failure. JAMA. 2011;306:2239-47.

17. Wachter R, Luers C, Kleta S, Griebel K, Herrmann-Lingen C, Binder L, et al Impact of diabetes on left ventricular diastolic function in patients with arterial hypertension. Eur J Heart Fail. 2007;9:469-76.

18. Grubitzsch H, Schaefer A, Melzer C, Wernecke KD, Gabbieri D, Konertz W Outcome after surgery for prosthetic valve endocarditis and the impact of preoperative treatment. J Thorac Cardiovasc Surg. 2014;148:2052-9.

19. Gaca JG, Sheng S, Daneshmand MA, O’Brien S, Rankin JS, Brennan JM, et al Outcomes for endocarditis surgery in North America: a simplified risk scoring system. J Thorac Cardiovasc Surg. 2011;141:98-106. e101-2.

20. Okazaki S, Yoshioka D, Sakaguchi M, Sawa Y, Mochizuki H, Kitagawa K. Acute ischemic brain lesions in infective endocarditis: incidence, related factors, and postoperative outcome. Cerebrovasc Dis. 2013;35:155-62.

21. Yoshioka D, Toda K, Okazaki S, Sakaguchi T, Miyagawa S, Yoshikawa Y, et al. Anemia is a risk factor of new intraoperative hemorrhagic stroke during valve surgery for endocarditis. Ann Thorac Surg. 2015;100:16-23.

22. Losser MR, Bernard C, Beaudeux J, Pison C, Payen D. Glucose modulates hemodynamic, metabolic, and inflammatory responses to lipopolysaccharide in rabbits. J Appl Physiol (1985). 1997;83:1566-74.

23. Geerlings SE, Hoepelman AI. Immune dysfunction in patients with diabetes mellitus (DM). FEMS Immunol Med Microbiol. 1999;26:259-65.

24. David TE, Gavra G, Feindel CM, Regesta T, Armstrong S, Maganti MD. Surgical treatment of active infective endocarditis: a continued challenge. J Thorac Cardiovasc Surg. 2007;133:144-9.

25. Yao F, Han L, Xu ZY, Zou LJ, Huang SD, Wang ZN, et al. Surgical treatment of multivalvular endocarditis: twenty-one-year single center experience. $J$ Thorac Cardiovasc Surg. 2009; 137:1475-80.

26. Renzulli A, Carozza A, Romano G, De Feo M, Della Corte A, Gregorio R, et al Recurrent infective endocarditis: a multivariate analysis of 21 years of experience. Ann Thorac Surg. 2001;72:39-43.

Key Words: endocarditis, diabetes mellitus, valve surgery 

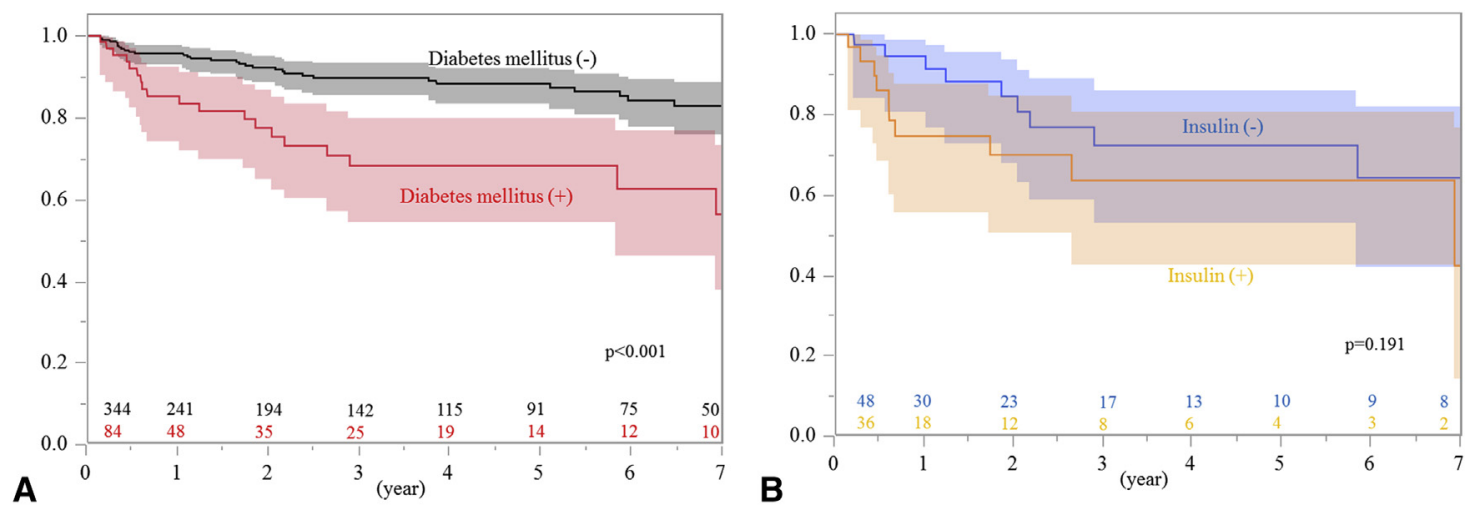

FIGURE E1. The Kaplan-Meier analysis of the overall survival after the first discharge and its $95 \%$ confidence interval. A, Patients without DM (black line) and patients with DM (red line). B, Patients without insulin use (blue line) and patients with insulin use (orange line).
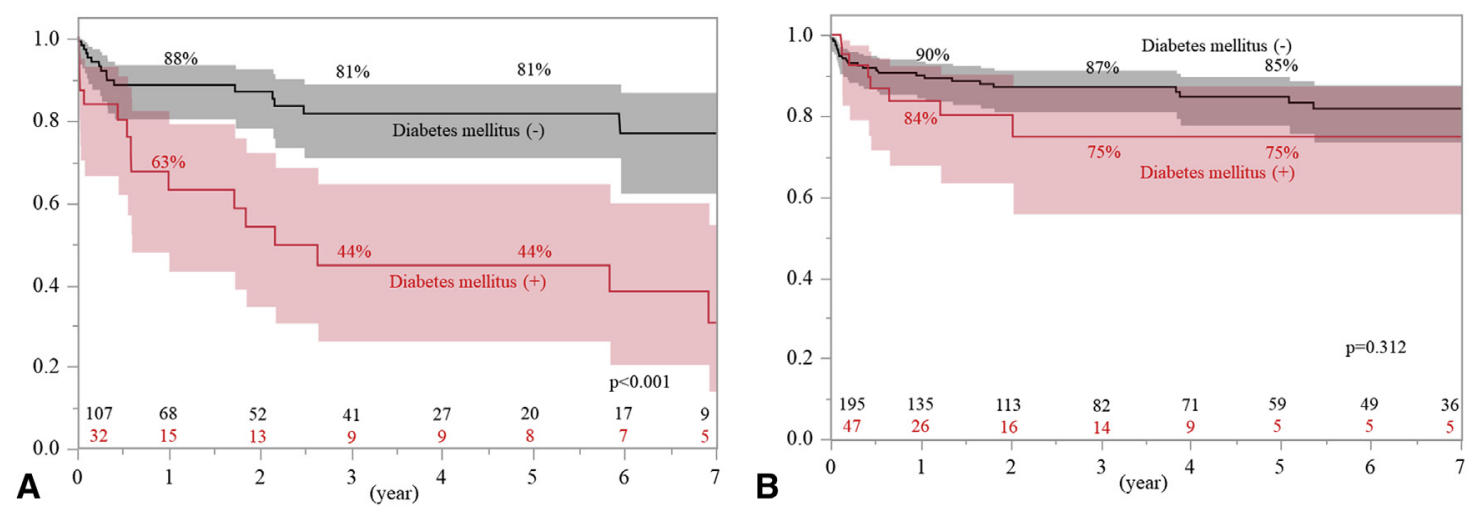

FIGURE E2. The Kaplan-Meier analysis of the overall survival and its $95 \%$ confidence interval between patients without DM (black line) and patients with DM (red line) in A, aortic valve endocarditis and B, mitral valve endocarditis. (Double valve endocarditis patients were excluded.)
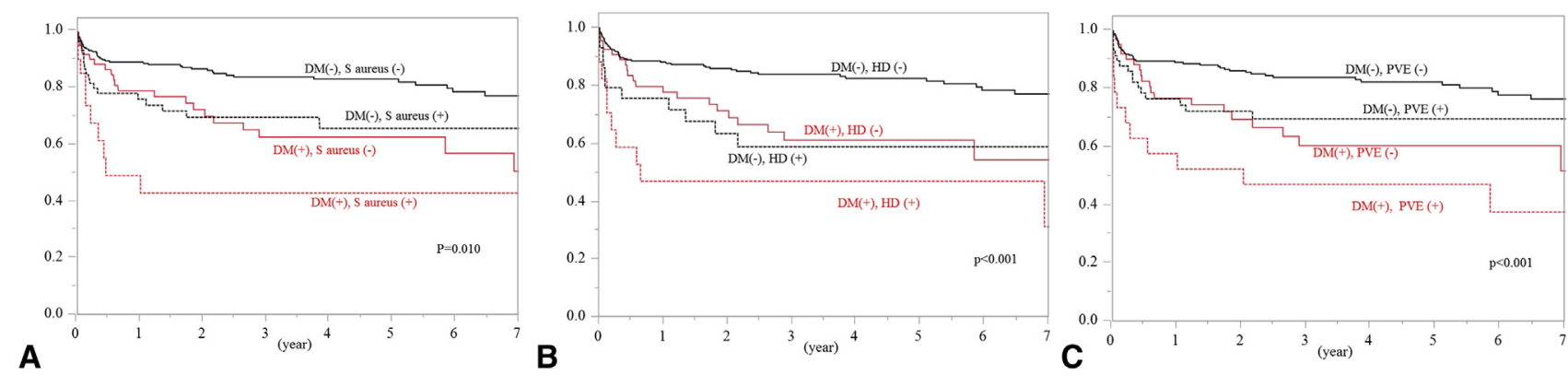

FIGURE E3. The Kaplan-Meier analysis of the overall survival rate according to the presence of diabetes mellitus and (A) Staphylococcus aureus infection; B, chronic hemodialysis; and (C) prosthetic valve endocarditis. $D M$, Diabetes mellitus; $H D$, chronic hemodialysis; $P V E$, prosthetic valve endocarditis. 

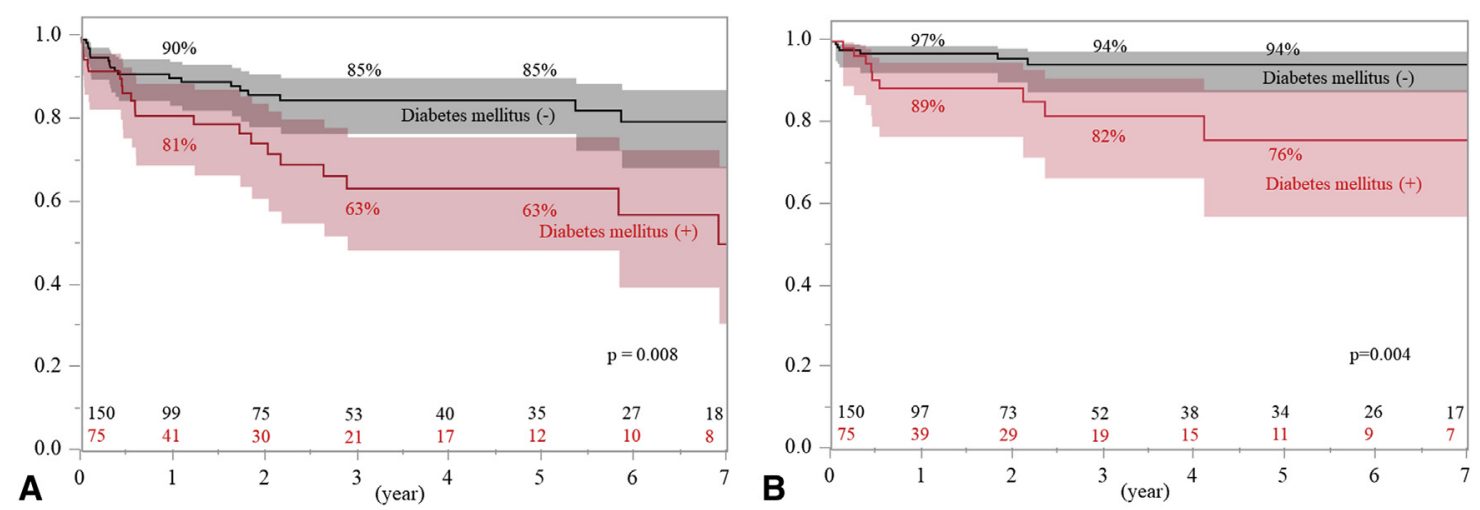

FIGURE E4. A, The Kaplan-Meier analysis of the overall survival and its $95 \%$ confidence interval between patients with and without DM in the propensity matched cohort. B, The Kaplan-Meier analysis of the rate of freedom from recurrence of endocarditis in the propensity matched cohort. Patients without DM (black line) and patients with DM (red line).

TABLE E1. List of participating hospitals in this multicenter study

Osaka University Hospital (Osaka, Japan)

Dokkyo Medical University Hospital (Tochigi, Japan)

Osaka Police Hospital (Osaka, Japan)

Osaka National Hospital (Osaka, Japan)

Osaka Prefectural General Hospital (Osaka, Japan)

JCHO Osaka Hospital (Osaka, Japan)

Fukui Cardiovascular Hospital (Fukui, Japan)

Higashi-Takarazuka Satoh Hospital (Hyogo, Japan)

Rinku General Hospital (Osaka, Japan)

Kansai Rosai Hospital (Hyogo, Japan)

Kinan Hospital (Wakayama, Japan)

Heart Institute Sakakibara Hospital (Okayama, Japan) 
TABLE E2. Variables enrolled in the univariate and multivariable analysis for risk factors

\begin{tabular}{|c|c|c|c|}
\hline \multirow{3}{*}{$\begin{array}{c}\text { Multiple regression model } \\
\text { In-hospital mortality }\end{array}$} & \multicolumn{3}{|c|}{ Cox hazard model } \\
\hline & \multicolumn{3}{|c|}{ Mortality after the first } \\
\hline & Overall mortality & discharge & Recurrence of endocarditis \\
\hline Age & Age & Age & Age \\
\hline Male & Male & Male & Male \\
\hline Body surface area & Body surface area & Body surface area & Body surface area \\
\hline Body mass index & Body mass index & Body mass index & Body mass index \\
\hline Atrial fibrillation & Atrial fibrillation & Atrial fibrillation & \\
\hline Diabetes mellitus & Diabetes mellitus & Diabetes mellitus & Diabetes mellitus \\
\hline Chronic hemodialysis & Chronic hemodialysis & Chronic hemodialysis & Chronic hemodialysis \\
\hline Preoperative stroke & Preoperative stroke & Preoperative stroke & \\
\hline \multirow[t]{2}{*}{ Preoperative heart failure } & Preoperative heart failure & Preoperative heart failure & \\
\hline & & & MRSA \\
\hline Staphylococcus aureus & Staphylococcus aureus & Staphylococcus aureus & Staphylococcus aureus \\
\hline Double valve involvement & Double valve involvement & Double valve replacement & Double valve replacement \\
\hline \multirow[t]{2}{*}{ Prosthetic valve endocarditis } & Prosthetic valve endocarditis & Prosthetic valve endocarditis & Prosthetic valve endocarditis \\
\hline & & & Use of mechanical valve \\
\hline $\begin{array}{l}\text { Laboratory valuables just } \\
\text { before surgery }\end{array}$ & $\begin{array}{l}\text { Laboratory valuables just } \\
\text { before surgery }\end{array}$ & & Reconstruction of annuls \\
\hline $\begin{array}{l}\text { White blood cell counts } \\
(\times 1000 / \mu \mathrm{L})\end{array}$ & $\begin{array}{l}\text { White blood cell counts } \\
\qquad(\times 1000 / \mu \mathrm{L})\end{array}$ & Perioperative stroke & Perioperative stroke \\
\hline Hemoglobin (g/dL) & Hemoglobin (g/dL) & Mediastinitis & Mediastinitis \\
\hline Platelets $(\times 10,000 / \mu \mathrm{L})$ & Platelets $(\times 10,000 / \mu \mathrm{L})$ & Need of CVVHD & Need of CVVHD \\
\hline C-reactive protein $(\mathrm{mg} / \mathrm{dL})$ & C-reactive protein $(\mathrm{mg} / \mathrm{dL})$ & & \\
\hline Total bilirubin (mg/dL) & Total bilirubin (mg/dL) & $\begin{array}{l}\text { Laboratory data } 2 \text { wk after } \\
\text { surgery }\end{array}$ & $\begin{array}{l}\text { Laboratory data } 2 \mathrm{wk} \text { after } \\
\text { surgery }\end{array}$ \\
\hline \multirow[t]{2}{*}{ eGFR $\left(\mathrm{mL} / \mathrm{min} / 1.73 \mathrm{~m}^{2}\right)$} & eGFR $\left(\mathrm{mL} / \mathrm{min} / 1.73 \mathrm{~m}^{2}\right)$ & $\begin{array}{l}\text { White blood cell counts } \\
\qquad(\times 1000 / \mu \mathrm{L})\end{array}$ & $\begin{array}{l}\text { White blood cell counts } \\
\qquad(\times 1000 / \mu \mathrm{L})\end{array}$ \\
\hline & & C-reactive protein $(\mathrm{mg} / \mathrm{dL})$ & C-reactive protein $(\mathrm{mg} / \mathrm{dL})$ \\
\hline $\begin{array}{l}\text { Preoperative } \\
\quad \text { echocardiography }\end{array}$ & $\begin{array}{l}\text { Preoperative } \\
\text { echocardiography }\end{array}$ & Total bilirubin (mg/dL) & Total bilirubin (mg/dL) \\
\hline LVDd (mm) & LVDd (mm) & eGFR $\left(\mathrm{mL} / \mathrm{min} / 1.73 \mathrm{~m}^{2}\right)$ & eGFR $\left(\mathrm{mL} / \mathrm{min} / 1.73 \mathrm{~m}^{2}\right)$ \\
\hline LVDs (mm) & LVDs (mm) & & \\
\hline \multirow[t]{6}{*}{$\operatorname{LVEF}(\%)$} & $\operatorname{LVEF}(\%)$ & $\begin{array}{l}\text { Postoperative } \\
\text { echocardiography }\end{array}$ & $\begin{array}{l}\text { Duration of postoperative } \\
\qquad \mathrm{ABx}(\mathrm{d})\end{array}$ \\
\hline & & LVDd (mm) & \\
\hline & & LVDs (mm) & $\begin{array}{l}\text { Postoperative } \\
\text { echocardiography }\end{array}$ \\
\hline & & LVEF $(\%)$ & LVDd (mm) \\
\hline & & & LVDs (mm) \\
\hline & & & LVEF (\%) \\
\hline
\end{tabular}

MRSA, Methicillin-resistant Staphylococcus aureus; $C V V H D$, continuous veno-venous hemodialysis; eGFR, estimated glomerular filtration rate; $L V D d$, left ventricular end-diastolic dimension; $L V D s$, left ventricular end-systolic dimension, $L V E F$, left ventricular ejection fraction; $A B x$, intravenous antibiotics therapy. 
TABLE E3. Change in laboratory data before and after surgery

\begin{tabular}{|c|c|c|c|c|c|c|}
\hline & \multicolumn{2}{|c|}{ Preoperative } & \multicolumn{4}{|c|}{ Postoperative } \\
\hline & $\begin{array}{l}\text { At the time of diagnosis } \\
\qquad(95 \% \mathbf{C I})\end{array}$ & $\begin{array}{c}\text { Before operation } \\
(95 \% \text { CI })\end{array}$ & $\begin{array}{c}1 \text { week } \\
(95 \% \mathrm{CI})\end{array}$ & $\begin{array}{l}2 \text { weeks } \\
(95 \% \mathrm{CI})\end{array}$ & $\begin{array}{c}4 \text { weeks } \\
(95 \% \mathrm{CI})\end{array}$ & $\begin{array}{l}8 \text { weeks } \\
(95 \% \mathrm{CI})\end{array}$ \\
\hline \multicolumn{7}{|l|}{$\begin{array}{l}\text { White blood cell counts, } \\
\quad \times 1000 / \mu \mathrm{L}\end{array}$} \\
\hline Diabetes mellitus (-) & $10.0(7.6-13.3)$ & $8.1(5.8-11.3)$ & $8.0(6.0-10.4)$ & $7.0(5.4-8.7)$ & $5.7(4.2-7.5)$ & $5.7(5.0-7.3)$ \\
\hline Diabetes mellitus (+) & $12.0(8.0-15.3)^{*}$ & $8.8(6.4-12.6)$ & $9.0(6.8-11.6)$ & $8.3(6.0-10.3)^{*}$ & $6.3(4.9-8.1)$ & $6.9(5.6-7.9)$ \\
\hline \multicolumn{7}{|l|}{ C-reactive protein, $\mathrm{mg} / \mathrm{dL}$} \\
\hline Diabetes mellitus (-) & $6.4(3.4-11.0)$ & $3.2(0.8-7.2)$ & $4.8(2.9-7.7)$ & $2.6(1.1-4.4)$ & $0.7(0.2-2.1)$ & $0.2(0.1-0.7)$ \\
\hline Diabetes mellitus $(+)$ & $7.9(4.5-12.5)$ & $4.5(1.5-10.3)^{*}$ & $5.5(3.8-9.0)$ & $3.0(1.4-6.8)$ & $1.0(0.4-3.4)$ & $0.5(0.2-1.6)^{*}$ \\
\hline \multicolumn{7}{|l|}{$\mathrm{eGFR}, \mathrm{mL} / \mathrm{min} / 1.73 \mathrm{~m}^{2}$} \\
\hline Diabetes mellitus (-) & $89(59-112)$ & $84(58-111)$ & $89(63-120)$ & $87(55-112)$ & $85(51-108)$ & $80(57-108)$ \\
\hline Diabetes mellitus $(+)$ & $60(32-91)^{*}$ & $57(34-90)^{*}$ & $64(32-90)^{*}$ & $65(35-92)^{*}$ & $67(30-92)^{*}$ & $69(31-88)^{*}$ \\
\hline \multicolumn{7}{|l|}{ Total bilirubin, $\mathrm{mg} / \mathrm{dL}$} \\
\hline Diabetes mellitus (-) & $0.7(0.5-1.0)$ & $0.6(0.4-0.9)$ & $0.7(0.5-1.2)$ & $0.6(0.4-0.9)$ & $0.5(0.4-0.8)$ & $0.5(0.4-0.6)$ \\
\hline Diabetes mellitus $(+)$ & $0.7(0.5-1.1)$ & $0.6(0.4-1.0)$ & $0.9(0.6-2.6)$ & $0.8(0.4-1.4)$ & $0.6(0.4-0.7)$ & $0.6(0.4-0.9)$ \\
\hline \multicolumn{7}{|c|}{ Lactate dehydrogenase, U/L } \\
\hline Diabetes mellitus (-) & $289(236-412)$ & $298(229-408)$ & $338(277-437)$ & $344(252-415)$ & $274(223-357)$ & $257(207-319)$ \\
\hline Diabetes mellitus $(+)$ & $310(249-373)$ & $309(262-371)$ & $349(315-406)$ & $305(243-375)$ & $266(209-357)$ & $258(213-278)$ \\
\hline
\end{tabular}

$C I$, Confidence interval; $e G F R$, estimated glomerular filtration rate. ${ }^{*} P<.05$ compared with diabetes mellitus ( - ).

TABLE E4. Preoperative risk factors for in-hospital mortality

\begin{tabular}{|c|c|c|c|c|}
\hline & \multicolumn{2}{|c|}{ Univariate } & \multicolumn{2}{|c|}{ Multivariate } \\
\hline & $\overline{\text { Odds ratio }(95 \% \mathrm{CI})}$ & $\overline{P \text { value }}$ & $\overline{\text { Odds ratio }(95 \% \mathrm{CI})}$ & $P$ value \\
\hline Age, $y$ & $1.06(1.03-1.09)$ & $<.001$ & $1.03(1.00-1.07)$ & .025 \\
\hline Chronic hemodialysis & $3.03(1.32-6.47)$ & .010 & $1.56(0.49-4.82)$ & .440 \\
\hline Diabetes mellitus & $1.71(0.81-3.42)$ & .143 & & \\
\hline Heart failure & $4.23(2.05-9.62)$ & $<.001$ & $3.47(1.45-9.34)$ & .005 \\
\hline Staphylococcus aureus infection & $3.68(1.87-7.17)$ & $<.001$ & $3.35(1.43-7.89)$ & .006 \\
\hline Prosthetic valve endocarditis & $2.66(1.30-5.28)$ & .009 & $3.10(1.30-7.40)$ & .012 \\
\hline Platelet counts, $\times 10,000 / \mu \mathrm{L}$ & $0.86(0.81-0.90)$ & $<.001$ & $0.89(0.81-0.90)$ & $<.001$ \\
\hline $\mathrm{eGFR}, \mathrm{mL} / \mathrm{min} / 1.73 \mathrm{~m}^{2}$ & $0.99(0.98-1.00)$ & .009 & $1.00(0.99-1.01)$ & 669 \\
\hline
\end{tabular}

$C I$, Confidence interval; $e G F R$, estimated glomerular filtration rate. 
TABLE E5. Risk factors for mortality after the first discharge

\begin{tabular}{|c|c|c|c|c|}
\hline & \multicolumn{2}{|c|}{ Univariate } & \multicolumn{2}{|c|}{ Multivariate } \\
\hline & Hazard ratio $(95 \% \mathrm{CI})$ & $P$ value & Hazard ratio $(95 \% \mathrm{CI})$ & $P$ value \\
\hline Age, y & $1.05(1.03-1.07)$ & $<.001$ & $1.07(1.03-1.10)$ & $<.001$ \\
\hline Diabetes mellitus & $2.80(1.57-4.83)$ & .001 & $2.02(1.02-3.83)$ & .043 \\
\hline Chronic hemodialysis & $2.86(1.44-5.27)$ & .004 & $2.26(0.78-6.41)$ & .133 \\
\hline Double valve replacement & $1.98(1.11-3.28)$ & .021 & $1.53(0.64-3.23)$ & .319 \\
\hline \multicolumn{5}{|c|}{ Laboratory valuables 2 wk after surgery } \\
\hline C-reactive protein, $\mathrm{mg} / \mathrm{dL}$ & $1.11(1.06-1.15)$ & $<.001$ & $1.10(1.04-1.15)$ & .001 \\
\hline $\mathrm{eGFR}, \mathrm{mL} / \mathrm{min} / 1.73 \mathrm{~m}^{2}$ & $0.99(0.98-0.99)$ & $<.001$ & $1.00(0.99-1.01)$ & .377 \\
\hline \multicolumn{5}{|c|}{ Postoperative echocardiographic parameters } \\
\hline LVEF, \% & $0.97(0.95-0.99)$ & .030 & $0.96(0.94-0.99)$ & .003 \\
\hline
\end{tabular}

$C I$, Confidence interval; $e G F R$, estimated glomerular filtration rate; $L V E F$, left ventricle ejection fraction. 